\title{
Tensile Behavior of Self-Compacting Steel Fiber Reinforced Concrete Evaluated by Different Test Methods
}

\author{
Xinxin Ding ${ }^{1, *}$, Changyong $\mathrm{Li}^{1}{ }^{1}$, Minglei Zhao ${ }^{2}, \mathrm{Jie} \mathrm{Li}^{2, *} \mathbb{C}$, Haibin Geng ${ }^{1}$ and Lei Lian ${ }^{3}$ \\ 1 International Joint Research Lab for Eco-building Materials and Engineering of Henan, School of Civil \\ Engineering and Communications, North China University of Water Resources and Electric Power, \\ Zhengzhou 450045, China; lichang@ncwu.edu.cn (C.L.); hbgeng@stu.ncwu.edu.cn (H.G.) \\ 2 School of Engineering, RMIT University, Melbourne, VIC 3001, Australia; s3339909@student.rmit.edu.au \\ 3 Changjiang Yichang Waterway Bureau, No. 273 Dongshan Avenue, Yichang 443500, China; \\ lian_lei0125@163.com \\ * Correspondence: dingxinxin@ncwu.edu.cn (X.D.); jie.li@rmit.edu.au (J.L.)
}

Citation: Ding, X.; Li, C.; Zhao, M.; Li, J.; Geng, H.; Lian, L. Tensile Behavior of Self-Compacting Steel Fiber Reinforced Concrete Evaluated by Different Test Methods. Crystals 2021, 11, 251. https://doi.org/ 10.3390/cryst11030251

Academic Editors: Sławomir J. J. Grabowski and Adam Stolarski

Received: 30 January 2021

Accepted: 25 February 2021

Published: 28 February 2021

Publisher's Note: MDPI stays neutral with regard to jurisdictional claims in published maps and institutional affiliations.

Copyright: () 2021 by the authors. Licensee MDPI, Basel, Switzerland. This article is an open access article distributed under the terms and conditions of the Creative Commons Attribution (CC BY) license (https:// creativecommons.org/licenses/by/ $4.0 /)$.

\begin{abstract}
Due to the mechanical properties related closely to the distribution of steel fibers in concrete matrix, the assessment of tensile strength of self-compacting steel fiber reinforced concrete (SFRC) is significant for the engineering application. In this paper, seven groups of self-compacting SFRC were produced with the mix proportion designed by using the steel fiber-aggregates skeleton packing test method. The hooked-end steel fibers with length of $25.1 \mathrm{~mm}, 29.8 \mathrm{~mm}$ and $34.8 \mathrm{~mm}$ were used, and the volume fraction varied from $0.4 \%$ to $1.4 \%$. The axial tensile test of notched sectional prism specimen and the splitting tensile test of cube specimen were carried out. Results show that the axial tensile strength was higher than the splitting tensile strength for the same self-compacting SFRC, the axial tensile work and toughness was not related to the length of steel fiber. Finally, the equations for the prediction of tensile strength of self-compacting SFRC are proposed considering the fiber distribution and fiber factor, and the adaptability of splitting tensile test for self-compacting SFRC is discussed.
\end{abstract}

Keywords: self-compacting SFRC; axial tensile strength; splitting tensile strength; notched section; axial tensile toughness; prediction

\section{Introduction}

The enhancement of steel fiber on the mechanical properties of concrete is affected by the mix proportion, fiber geometric characteristics and distribution pattern [1-3]. This directly affects the loading behaviors of reinforced concrete components including beams and slabs with the presence of steel fibers [4-8]. Compared with vibrated steel fiber reinforced concrete (SFRC), self-compacting SFRC is made with more contents of cementitious materials and fine aggregate, and smaller particle size of coarse aggregate [9-11]. This leads to the different fiber distribution and aggregate skeleton of self-compacting SFRC from those of vibrated SFRC, which further leads to the different tensile properties of self-compacting SFRC [1,12-14].

Splitting tensile test and axial tensile test are common test methods for the tensile strength of concrete. Meanwhile, the axial tensile stress-strain curve and the tensile toughness of concrete can be gotten from the axial tensile test [15]. However, restricted by the stiffness and clamping conditions of testing machine, the size and shape of axial tensile specimens are various, and the failure interface may appear in the non-tested crosssection [16-18]. Splitting tensile test is often used in research and practical engineering due to its easy operation, simple test process and low requirement for stiffness of testing machine [19]. This method is built upon the assumption that the uniform distribution of horizontal stress exists in the splitting section, except part of section closed to the splitting strips on top and bottom surfaces of the specimen. For conventional concrete close to 
brittle material, this assumption is adaptable to get a relatively accurate result of tensile strength, which is always slightly higher than the axial tensile strength [20]. However, it is no longer fully applicable for SFRC due to the steel fibers involved in tensile work. With the development of a cracking section of splitting tensile specimen, the stress distribution becomes complex with the restrained local area of steel fiber near the splitting surface. The experimental studies on vibrated SFRC $[17,21]$ indicated that, the enhancing coefficient of steel fiber on the axial tensile strength is less than that on the splitting tensile strength, and the ratio of axial tensile strength to splitting tensile strength decreases with the increase of fiber factor and the concrete compressive strength. The ductile behavior of the SFRC leads to a large compressive zone under the loading strip in the splitting tensile test, which makes the load distributed unevenly in the load direction [21].

At present, the splitting tensile test and axial tensile test are commonly used to determine the tensile strength of self-compacting SFRC. Ghanbarpour [13] reported that the ratio of splitting tensile strength to compressive strength for self-compacting SFRC is lower than that of vibrated SFRC, due to the characteristic of finer raw materials in selfcompacting SFRC. Akcay and Tasdemir [1] presented that both the splitting tensile strength and flexural strength of self-compacting SFRC increased linearly with the volume fraction of steel fiber, while the increasing rate of flexural strength was higher due to the trends of steel fibers oriented along the bending direction; the effect of tensile strength of steel fiber on the splitting tensile strength was not obvious, but on the flexural strength was significant. Khala and Nazari [22] reported that the splitting tensile strength of self-compacting SFRC was improved with the randomly oriented steel fibers up to volume fraction of $1.2 \%$. The study of You et al. [23] on the axial tensile strength of self-compacting SFRC by using notched prism specimen showed that, the axial tensile strength was enhanced obviously with longer fiber, and the growth tended to be stable or even decreased with the increasing volume fraction of steel fiber. Clifford et al. [24] reported that compared to the selfcompacting SFRC with single hooked-end steel fiber and microfiber, the self-compacting SFRC with double hooked-end steel fiber and microfiber had higher axial tensile strength, lower fracture energy, smaller cracking strain and ultimate strain. Cunha et al. [25] studied the axial tensile properties of self-compacting SFRC by using notched cylinder specimen. Results indicated that the tensile properties after-cracking correlated positively with the effective number of bridged fibers in the failure section, pseudo strain hardening was observed in the descending portion of axial tensile stress-strain curve for self-compacting SFRC due to the pulling out of most bridged fibers, the residual tensile stress reduced significantly with the breakage of most bridged fibers. The study of Liao et al. [26] on the axial tensile properties of self-compacting SFRC by using large-end specimens presented that, with the hooked-end steel fiber in volume fraction from $0.38 \%$ to $1.96 \%$, pseudo strain hardening appeared on the tensile stress-strain curve, and the failure was accompanied by multi-cracks.

Based on the above analyses, the comparative research is rare on splitting tensile strength and axial tensile strength of self-compacting SFRC, the axial tensile stress-strain curves of self-compacting SFRC are also short of experimental data. These efforts need to be enriched to facilitate the engineering application of self-compacting SFRC. In this paper, the self-compacting SFRC was produced based on the steel fiber-aggregates skeleton packing test method, in which the amount of cementitious material and reasonable sand ratio are related to the fiber factor. The axial tensile test was carried out using notched prism specimen to control the cracking section and to eliminate the wall effect of steel fiber on the tensile properties of self-compacting SFRC $[16,18]$. The splitting tensile test was carried out using cube specimen. With the comparison of test results, the influence of test methods on the tensile strength of self-compacting SFRC is studied. Finally, the practicability of the splitting tensile test method used for self-compacting SFRC is evaluated. 


\section{Materials and Methods}

\subsection{Raw Materials}

All of the raw materials are the same as the former research [27]. The cement was grade P.O 42.5 ordinary silicate cement with density of $3085 \mathrm{~kg} / \mathrm{m}^{3}$, compressive strength at $28 \mathrm{~d}$ of $54.7 \mathrm{MPa}$ and flexural strength at $28 \mathrm{~d}$ of $9.43 \mathrm{MPa}$. The class-II fly ash was used as the mineral admixture with density of $2349 \mathrm{~kg} / \mathrm{m}^{3}$ and activity index of $80.9 \%$.

The coarse aggregate was crushed limestone in continuous grading with the particle sizes of $5-16 \mathrm{~mm}$, the apparent density of $2736 \mathrm{~kg} / \mathrm{m}^{3}$, the bulk density of $1529 \mathrm{~kg} / \mathrm{m}^{3}$, and the crush index of $12.2 \%$.

The fine aggregate was manufactured sand with the fineness modulus of 2.73 , the apparent density of $2740 \mathrm{~kg} / \mathrm{m}^{3}$, the bulk density of $1620 \mathrm{~kg} / \mathrm{m}^{3}$, and the stone-powder content of $7.3 \%$.

The water reducer was high-performance polycarboxylic acid type with measured water-reducing rate of $30 \%$ and solid content of $35 \%$. The mix water was tap-water of Zhengzhou, China.

The hooked-end steel fibers with three different lengths were used, and identified as $\mathrm{HFa}, \mathrm{HFb}$ and $\mathrm{HFc}$, respectively. All fibers had a diameters $d_{\mathrm{f}}$ of $0.5 \mathrm{~mm}$ and tensile strength of $1150 \mathrm{MPa}$. The measured length $l_{\mathrm{f}}$ was $25.1 \mathrm{~mm}, 29.8 \mathrm{~mm}$ and $34.8 \mathrm{~mm}$, and the fiber aspect ratio $l_{\mathrm{f}} / d_{\mathrm{f}}$ was 50,60 and 70, successively. The numbers of steel fibers per kilogram were 25,861, 21,637 and 18,546.

\subsection{Preparation of Self-Compacting SFRC}

The mix proportion of self-compacting SFRC was designed by using the steel fiberaggregates skeleton packing test method [28,29]. Six groups of self-compacting SFRC were designed with the volume fraction of steel fiber $v_{\mathrm{f}} \mathrm{F} 0.4 \%, 0.8 \%, 1.2 \%, 1.4 \%, 1.2 \%$ and $1.2 \%$, and successively identified as $\mathrm{HFb} 04, \mathrm{HFb} 08, \mathrm{HFb} 12, \mathrm{HFb} 14, \mathrm{HFa} 12$ and HFc12. The length and the volume fraction of steel fiber were considered as main factors. The water to binder ratio $w / b$ is constant of 0.31 , the content of fly ash was $30 \%$ of the total mass of binders, the sand ratios changed rationally with the fiber factor $\lambda_{\mathrm{f}}$. The fiber factor is the product of the volume fraction and the aspect ratio of steel fiber. That is, $\lambda_{\mathrm{f}}=v_{\mathrm{f}} \cdot l_{\mathrm{f}} / d_{\mathrm{f}}$. Detailed mix proportion of which, are presented in Table 1. One group of self-compacting concrete (SCC) without steel fiber was used as the reference concrete.

Table 1. Detailed mix proportion of self-compacting (steel fiber reinforced concrete) SFRC and reference (self-compacting concrete) SCC.

\begin{tabular}{|c|c|c|c|c|c|c|c|}
\hline Concrete & SCC & HFb04 & HFb08 & HFb12 & HFb14 & HFa12 & HFc12 \\
\hline$w / b$ & 0.31 & 0.31 & 0.31 & 0.31 & 0.31 & 0.31 & 0.31 \\
\hline Sand ratio $\beta_{\mathrm{s}}(\%)$ & 50 & 52 & 54 & 56 & 57 & 55 & 57 \\
\hline Fly ash content (\%) & 30 & 30 & 30 & 30 & 30 & 30 & 30 \\
\hline \multirow{2}{*}{ Steel fiber $v_{\mathrm{f}}$} & - & $\mathrm{HFb}$ & $\mathrm{HFb}$ & $\mathrm{HFb}$ & $\mathrm{HFb}$ & $\mathrm{HFa}$ & $\mathrm{HFC}$ \\
\hline & 0 & 0.4 & 0.8 & 1.2 & 1.4 & 1.2 & 1.2 \\
\hline Water $\left(\mathrm{kg} / \mathrm{m}^{3}\right)$ & 192 & 201 & 210 & 219 & 223 & 214 & 223 \\
\hline Cement $\left(\mathrm{kg} / \mathrm{m}^{3}\right)$ & 433 & 454 & 474 & 494 & 504 & 484 & 504 \\
\hline Fly ash $\left(\mathrm{kg} / \mathrm{m}^{3}\right)$ & 186 & 194 & 203 & 214 & 216 & 207 & 216 \\
\hline Crushed stone $\left(\mathrm{kg} / \mathrm{m}^{3}\right)$ & 751 & 675 & 601 & 527 & 491 & 553 & 502 \\
\hline Sand $\left(\mathrm{kg} / \mathrm{m}^{3}\right)$ & 751 & 763 & 774 & 783 & 788 & 784 & 782 \\
\hline Water-reducer $\left(\mathrm{kg} / \mathrm{m}^{3}\right)$ & 5.57 & 5.51 & 5.42 & 5.30 & 5.40 & 5.19 & 5.40 \\
\hline Steel fiber $\left(\mathrm{kg} / \mathrm{m}^{3}\right)$ & 0 & 31.4 & 62.8 & 94.2 & 109.9 & 94.2 & 94.2 \\
\hline
\end{tabular}

The mixture was mixed by a horizontal shaft forced-mixer. The cement, fly ash, manufactured sand and one-third of the water were mixed firstly for $1 \mathrm{~min}$, and then the residual water mixed with water-reducer was added to mix for $3 \mathrm{~min}$. After that, the crushed limestone and the steel fiber were added successively and mixed at least for $4 \mathrm{~min}$. 
The workability of fresh concrete was measured in accordance with the specification of China code JGJ/T 283 [29]. The slump flow of SCC, HFb04, HFb08, HFb12, HFb14, and HFa12 were ranged from $630 \mathrm{~mm}$ to $685 \mathrm{~mm}$. The slump flow time $T_{500}$ ranged from $4.33 \mathrm{~s}$ to $6.28 \mathrm{~s}$, which is the time from the beginning of lifting the slump cone to the slump flow of fresh concrete reaching at $500 \mathrm{~mm}$. It means that the six groups of fresh concretes are fit for constructing of the conventional reinforced concrete structures. HFc12 has slump flow of $560 \mathrm{~mm}$ and the flow time $T_{500}$ of $6.71 \mathrm{~s}$, which is fit for constructing of the concrete structures without reinforcement or with a minor amount of reinforcement.

\subsection{Test Method}

The splitting tensile strength of self-compacting SFRC was in accordance with the specification of China code GB50081 [19]. Three cube specimens with dimension of $150 \mathrm{~mm}$ were used as a group in the splitting test. A total of 21 cube specimens were cured in standard curing room for 90 days. Figure 1 presents the specimen with splitting strips. The test was carried out by a servo hydraulic universal testing machine made by SANS Co. Ltd. with maximum load of $600 \mathrm{kN}$. The loading direction was opposite to the gravity direction, and the loading speed was $2 \mathrm{kN} / \mathrm{s}$. The test was finished with the splitting tensile fracture of the specimen.

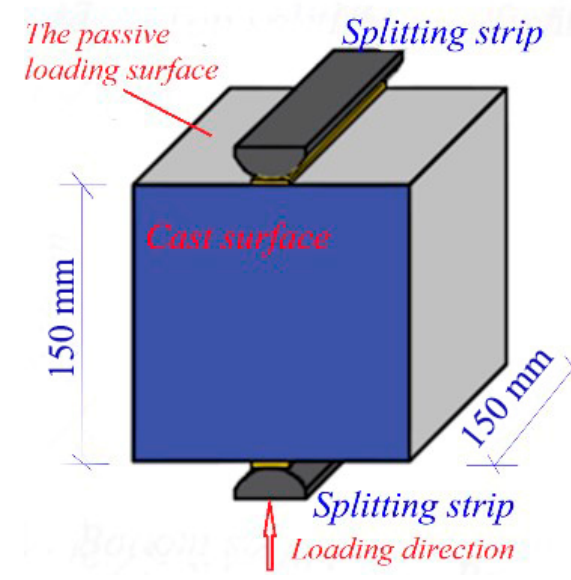

Figure 1. Specimens of splitting tensile test.

The axial tensile test was in accordance with the specification of China code CECS13 [15] Three prism specimens as a group were used in the axial tensile test. As presented in Figure 2, the specimens were prisms with the centrally embedded tensile bars at the ends. The dimension of the prism was $150 \mathrm{~mm} \times 150 \mathrm{~mm} \times 550 \mathrm{~mm}$. A total of 21 prism specimens were cured at standard curing room for 90 days. Referenced to the treatment method specified in RILEM TC-162 [30], the notch around cross-section of prism was cute before testing to eliminate the "wall effect" of steel fibers [15,31]. The notch was $25 \mathrm{~mm}$ deep and $10 \mathrm{~mm}$ wide. The notch section was square with side length of $100 \mathrm{~mm}$. 


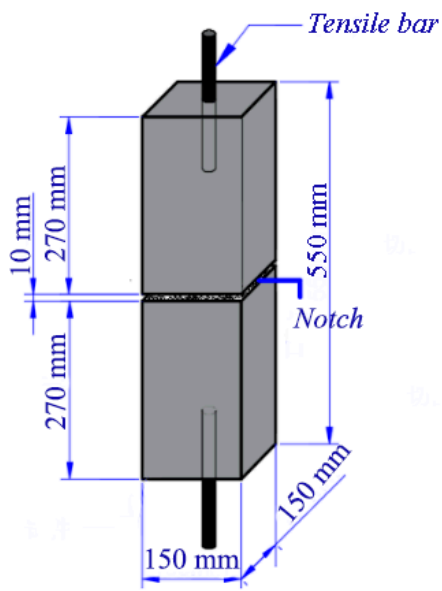

(a)

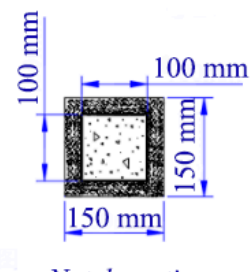

(b)

Figure 2. Specimens of axial tensile test: (a) notched specimen with tensile bars; (b) notch section of specimen.

The axial tensile test was carried out by a servo hydraulic universal testing machine with maximum load of $600 \mathrm{kN}$. As presented in Figure 3, the steel bars embedded in the ends of specimens were linked with the spherical universal hinge device of testing machine to eliminate the eccentricity effect [15,32]. Two LVDTs with measure scope of $5 \mathrm{~mm}$, identified as LVDT1, and two LVDTs with measure scope of $20 \mathrm{~mm}$, identified as LVDT2, were used to ensure the measuring precision and range simultaneously. After the specimen was fixed on the testing machine, four LVDTs were installed near the corner of specimen by using the fixing rings. The load and four displacements were collected synchronously and independently during the loading process. The average of four displacements was used as the measured deformation of the specimen. The tensile stress-strain curve was drawn based on the test results. The tensile stress was computed by the load on notch section, the tensile strain was computed with the gauge length of $150 \mathrm{~mm}$. The loading speed was $0.1 \mathrm{~mm} / \mathrm{min}$, and the test was finished with the axial tensile fracture of the specimen.

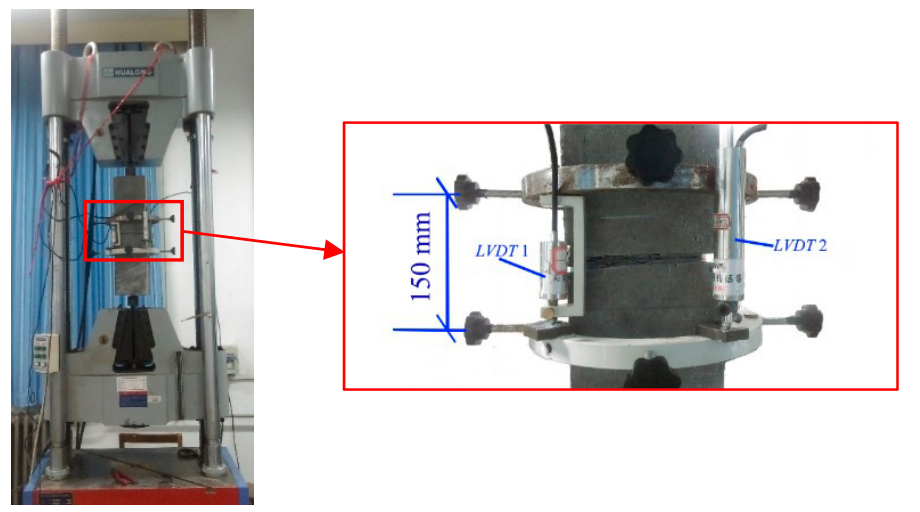

Figure 3. Testing machine and device for axial tensile strength of concrete.

\section{Test Results and Discussion}

\subsection{Splitting Tensile Test}

3.1.1. Test Phenomena

The specimen of the SCC broke into two parts due to the brittle cracking, the crack passed through both aggregates and hardened cement paste to form a flat failure surface. However, the different failure pattern appeared on the self-compacting SFRC specimens and the crushed zone are emphasized with red lines in Figure 4. Local splitting cracks first turned on the specimen near the splitting strips when the load reached a certain 
value, and the steel fibers bridging the cracks redistributed the tensile stress of the cracked SFRC matrix. The splitting section continuously cracked under the increased load, and the splitting failure presented a ductile feature with the development of the bond-slip of steel fiber [32]. The width of splitting crack decreased along with the direction from the passive loading surface to the active loading surface. With the increase of volume fraction of steel fiber, the crack width and the crushed zone of the specimen on the passive loading surface decreased significantly. This indicates that the more complex stress distribution took place on the splitting section of specimen of self-compacting SFRC.

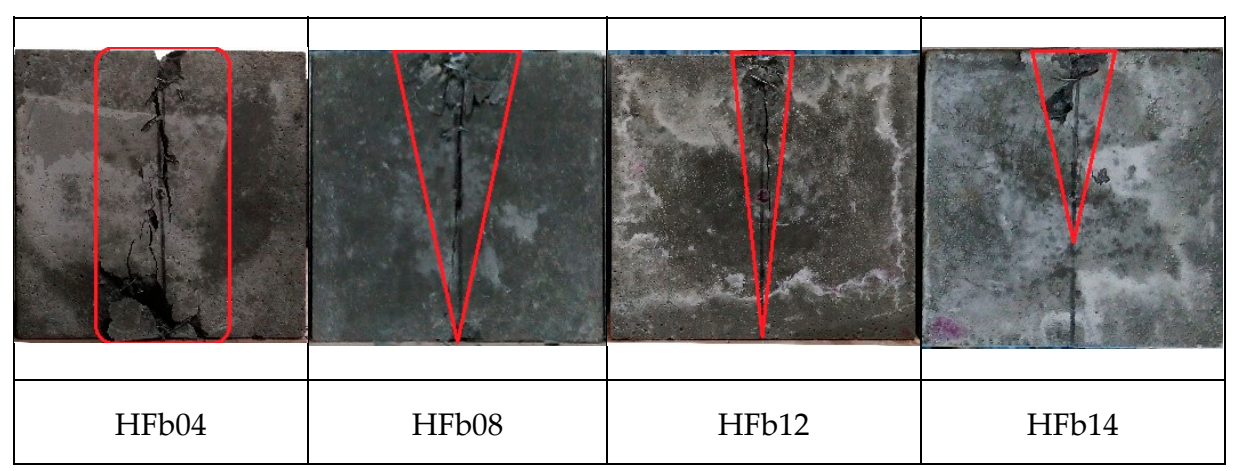

Figure 4. Failure patterns of splitting tensile specimens with the crushed zone emphasized by red lines.

\subsubsection{Splitting Tensile Strength}

The splitting tensile strength $f_{\text {st }}$ could increase by $3.4 \sim 15.9 \%$ with the volume fraction of steel fiber $\mathrm{HFb}$ increased to be $1.2 \%$. With the same $v_{\mathrm{f}}=1.2 \%$, the $f_{\text {st }}$ increased by $10.9 \%$ with the fiber length increased from $25.1 \mathrm{~mm}$ to $34.8 \mathrm{~mm}$. The changes of the splitting tensile strength $f_{\text {st }}$ of self-compacting SFRC with fiber factor $\lambda_{\mathrm{f}}$ is drawn in Figure 5. This indicates that a direct proportional linear relationship between $f_{\mathrm{st}}$ and $\lambda_{\mathrm{f}}$ can be fitted out, and presented as Equation (1) based on previous study [31],

$$
f_{\mathrm{st}}=f_{\mathrm{st}, 0}\left(1+\alpha_{\mathrm{tb}} \alpha_{\mathrm{te}} \lambda_{\mathrm{f}}\right)
$$

where, $\alpha_{\mathrm{te}}$ is a coefficient related to the fiber distribution, $\alpha_{\mathrm{te}}=0.441$ [31]; $\alpha_{\mathrm{tb}}$ is the comprehensive coefficient of other factors affecting the bridging effect of steel fiber in the splitting tensile test; $f_{\mathrm{st}, 0}$ is the splitting tensile strength of SCC.

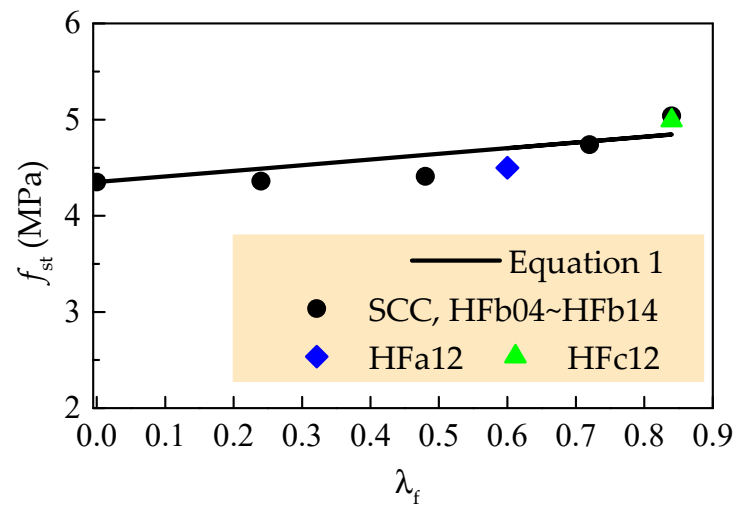

Figure 5. Changes of the splitting tensile strength with fiber factor.

By fitting the test data of $f_{\mathrm{st}}$ in this paper, the coefficient $\alpha_{\mathrm{tb}}$ is 0.307 . Figure 5 presents the comparison of test and calculation values of $f_{\mathrm{st}}$. The average ratio is 1.008 with a dispersion coefficient of 0.035 . 


\subsection{Axial Tensile Test}

\subsubsection{Test Phenomena}

Typical failure patterns of axial tensile specimens of self-compacting SFRC are presented in Figure 6. Similar to the failure of notched cylinders [25], two failure modes were observed in this test: one mode was the breakage of bridged steel fibers, another was the pulling of bridged fiber out of the SFRC matrix. The former was observed in specimens of $\mathrm{HFb} 04$, and the latter was observed in specimens of $\mathrm{HFb} 08, \mathrm{HFb} 12, \mathrm{HFb} 14, \mathrm{HFa} 12$ and HFc12. This indicates that the bridged steel fibers were subjected to the tensile force which released from the cracked SFRC matrix. When the bridged steel fibers were insufficient to bear the tensile force, they would be broken with the suddenly overloading. Otherwise, the bridged steel fibers could continuously bear the tension to produce the bond-slip until pull out.
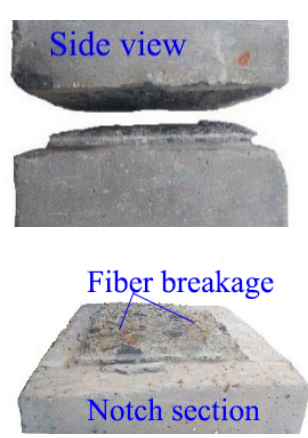

(a)

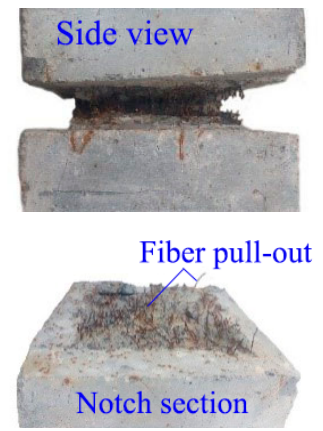

(b)

Figure 6. Typical failure patterns of axial tensile specimens: (a) fiber breakage of HFb04; (b) fiber pull-out of $\mathrm{HFb} 12$.

\subsubsection{Axial Tensile Strength and Stress-strain Curve}

The axial tensile stress-strain curves of self-compacting SFRC are presented in Figure 7. Due to difficult control in the post-peak region at the axial tensile test, specimens of SCC and $\mathrm{HFb} 04$ had no descending portion of axial tensile stress-strain curve. For specimen $\mathrm{HFb} 08$ with $v_{\mathrm{f}}=0.8 \%$, a sharp drop existed on the stress-strain curve once the load reached the initial cracking resistance of the notch section, of which the initial cracking strength is the axial tensile strength. For specimens of HFb12, HFb14, HFa12 and HFc12 with $v_{\mathrm{f}} \geq 1.2 \%$, the descending portion of axial tensile stress-strain curves became gently with the gradually pulling out of steel fibers. Due to enough steel fibers bridged on notch section, the cracking load could be sustained or even increased slightly with the increase of tensile strain. This leads an increased axial tensile strength of self-compacting SFRC with the increasing volume fraction of steel fiber.

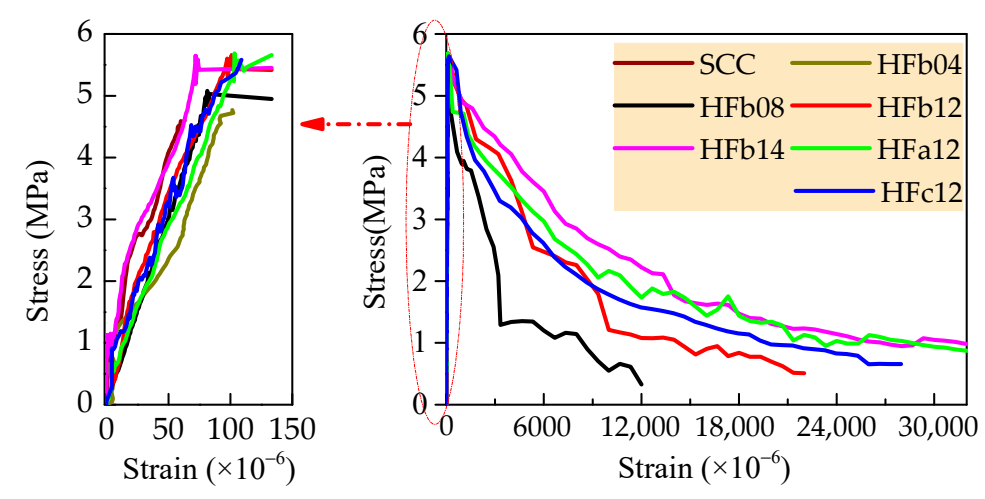

Figure 7. The axial tensile stress-strain curves of self-compacting SFRC. 
With the increase of fiber length compared with HFa, the number of steel fiber per kilogram of $\mathrm{HFb}$ and $\mathrm{HFc}$ reduced by $19.5 \%$ and $39.4 \%$. This led a reduction of the presence of steel fiber on notch section. As a result, the loading capacity of bridged steel fiber on notch section reduced after cracking. HFa has higher loading capacity with the same strain compared with $\mathrm{HFb}$ and HFc. This indicates the initial descending of the stress-strain curve dropped sharply with the increasing length of steel fiber. The stable presentation of stress-strain curves at descending portion are related to the better bond properties of hooked-end steel fiber in SFRC matrix [32].

The axial tensile test results of self-compacting SFRC are presented in Table 2. $f_{\text {fcr }}$ is the initial cracking tensile strength of self-compacting SFRC, which is calculated with the initial cracking load divided by the notch section area of the specimen. $f_{\mathrm{fa}}$ is the peak tensile stress after the cracking of the notched specimen, which is calculated with the maximum load after cracking divided by the notch section area of the specimen. $\varepsilon_{\mathrm{fcr}}$ is the initial cracking tensile strain corresponding to $f_{\mathrm{fcr}} . \varepsilon_{\mathrm{fa}}$ is the tensile strain corresponding to $f_{\mathrm{fa}}$. According to China code CECS13 [15], the axial tensile strength $f_{\text {at }}$ is larger one of $f_{\text {fcr }}$ and $f_{\mathrm{fa}}, \varepsilon_{\mathrm{at}}$ is the strain corresponded to the axial tensile strength.

Table 2. Test results of axial tensile strength and strain.

\begin{tabular}{|c|c|c|c|c|c|c|c|}
\hline Item & SCC & $\mathrm{HFb04}$ & HFb08 & $\mathrm{HFb} 12$ & $\mathrm{HFb} 14$ & HFa12 & HFc12 \\
\hline \multicolumn{8}{|l|}{ Strengths } \\
\hline$f_{\text {fcr }}(\mathrm{MPa})$ & 4.59 & 4.77 & 5.08 & 5.55 & 5.65 & 5.69 & 5.52 \\
\hline$f_{\mathrm{fa}}(\mathrm{MPa})$ & - & - & - & 5.66 & 5.59 & 5.66 & 5.64 \\
\hline$f_{\text {at }}(\mathrm{MPa})$ & 4.59 & 4.77 & 5.08 & 5.66 & 5.65 & 5.69 & 5.64 \\
\hline \multicolumn{8}{|c|}{ Corresponding strains } \\
\hline$\varepsilon_{\mathrm{fcr}}\left(10^{-6}\right)$ & 63.3 & 95.3 & 81.4 & 91.7 & 70.3 & 103.4 & 102.6 \\
\hline$\varepsilon_{\mathrm{fa}}\left(10^{-6}\right)$ & & - & - & 101.1 & 73.5 & 133.3 & 160.3 \\
\hline$\varepsilon_{\mathrm{at}}\left(10^{-6}\right)$ & 63.3 & 95.3 & 81.4 & 101.1 & 70.3 & 103.4 & 160.3 \\
\hline
\end{tabular}

Due to the brittle fracture after cracking, no values of $f_{\mathrm{fa}}$ were measured for the specimens with $v_{\mathrm{f}} \leq 0.8 \%$. For other specimens with $v_{\mathrm{f}} \geq 1.2 \%$, the values of $f_{\mathrm{fcr}}$ and $f_{\mathrm{fa}}$ are almost the same, while the strains $\varepsilon_{\mathrm{fcr}}$ and $\varepsilon_{\mathrm{fa}}$ increased slightly with the increasing volume fraction of steel fiber. This provides a good tension resistance of specimen with larger deformation.

The axial tensile strength $f_{\text {at }}$ keeps a linear growth with the increase of fiber factor. $f_{\text {at }}$ increases by $22.8-23.9 \%$ with the volume fraction of steel fiber $\mathrm{HFb}$ increased up to $1.2 \%$. With the same $v_{\mathrm{f}}=1.2 \%$, the axial tensile strength $f_{\text {at }}$ decreases slightly with different fiber length. Figure 8 exhibits the changes of the axial tensile strength of self-compacting SFRC with the fiber factor $\lambda_{\mathrm{f}}$. This indicates that a direct proportional linear relationship between $f_{\text {at }}$ and $\lambda_{\mathrm{f}}$ can be fitted out. Therefore, the prediction of axial tensile strength of self-compacting SFRC considering fiber distribution can be done with Equation (2),

$$
f_{\mathrm{at}}=f_{\mathrm{at}, 0}\left(1+\alpha_{\mathrm{ta}} \alpha_{\mathrm{te}} \lambda_{\mathrm{f}}\right)
$$

where, $\alpha_{\mathrm{te}}$ is the influence coefficient of fiber distribution, $\alpha_{\mathrm{te}}=0.441$ [31]; $\alpha_{\mathrm{ta}}$ is the comprehensive coefficient of other factors affecting the bridging effect of steel fiber in the axial tensile test; $f_{\mathrm{at}, 0}$ is the axial tensile strength of SCC. 


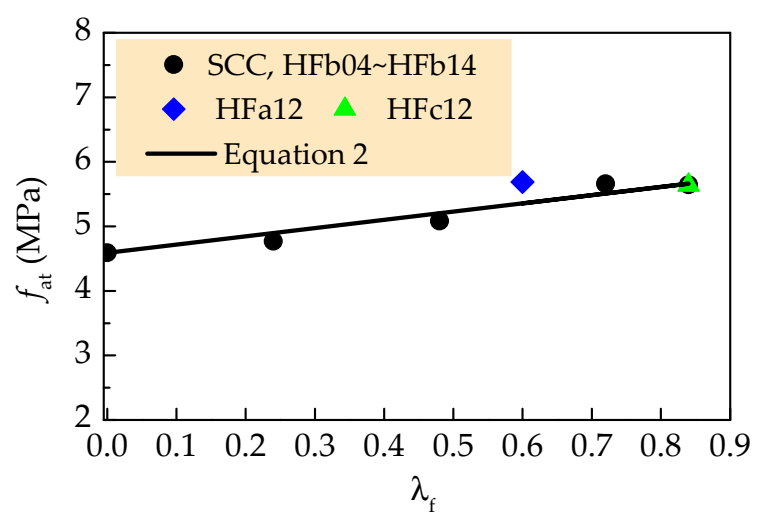

Figure 8. Axial tensile strength as a function of the fiber content.

By fitting the test data of $f_{\text {at }}$ in this paper, $\alpha_{\text {ta }}$ is 0.631 . Figure 8 presents the comparison of test and calculation values of $f_{\text {at }}$. The average ratio is 0.998 with a dispersion coefficient of 0.084 .

\subsubsection{Axial Tensile Toughness}

According to the specification of China code CECS 13 [15], the tension work $W_{\mathrm{f}, 0.2}$ is the area under the axial tensile load-deformation curve. The maximum deformation of $0.3 \mathrm{~mm}$ is calculated by 0.2 times of gauge length $l_{0}=150 \mathrm{~mm}$. The axial tensile toughness ratio $R_{\mathrm{fe}, 0.2}$ is calculated by Equation (3).

$$
R_{\mathrm{fe}, 0.2}=\frac{W_{\mathrm{f}, 0.2}}{0.2 \% l_{0} f_{\mathrm{at}} A}
$$

Where, $A$ is the notch section area of the specimen.

From the axial tensile load-deformation curves presented in Figure 9, the calculation results of $W_{\mathrm{f}, 0.2}$ and $R_{\mathrm{fe}, 0.2}$ are shown in Figure 10. The positive correlations exist for $W_{\mathrm{f}, 0.2}$ and $R_{\mathrm{fe}, 0.2}$ with the fiber factor $\lambda_{\mathrm{f}}$ of $\mathrm{HFb}$ steel fiber, due to the more pull-out work needed to be exerted on the notch section of specimen with more steel fibers. However, no obvious relationships were observed in $W_{\mathrm{f}, 0.2}$ and $R_{\mathrm{fe}, 0.2}$ of self-compacting SFRC with the fiber length, as the hooked-end rather than fiber length plays a role controlling the bond performance in self-compacting SFRC [32].
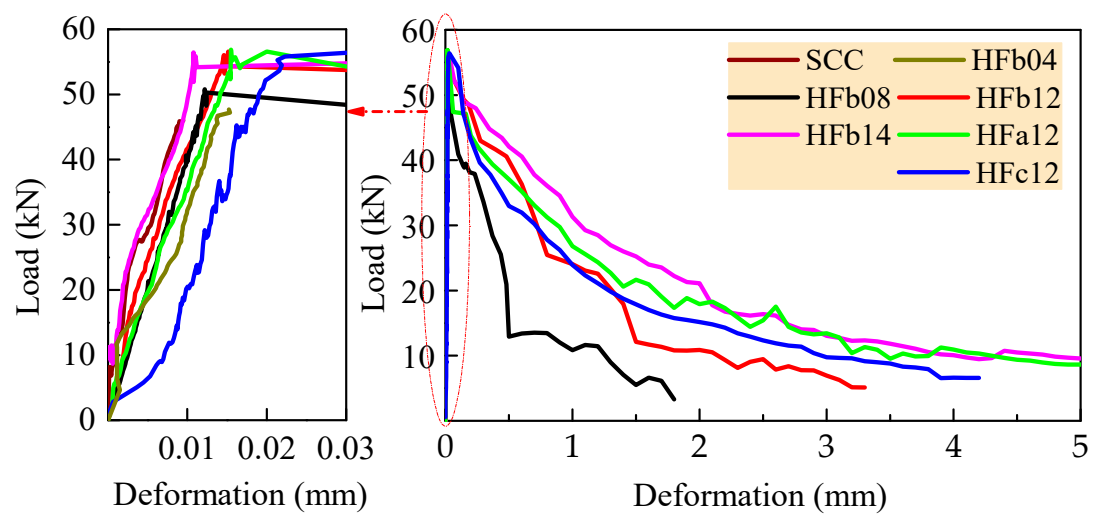

Figure 9. The axial tensile load-deformation curves of self-compacting SFRC. 


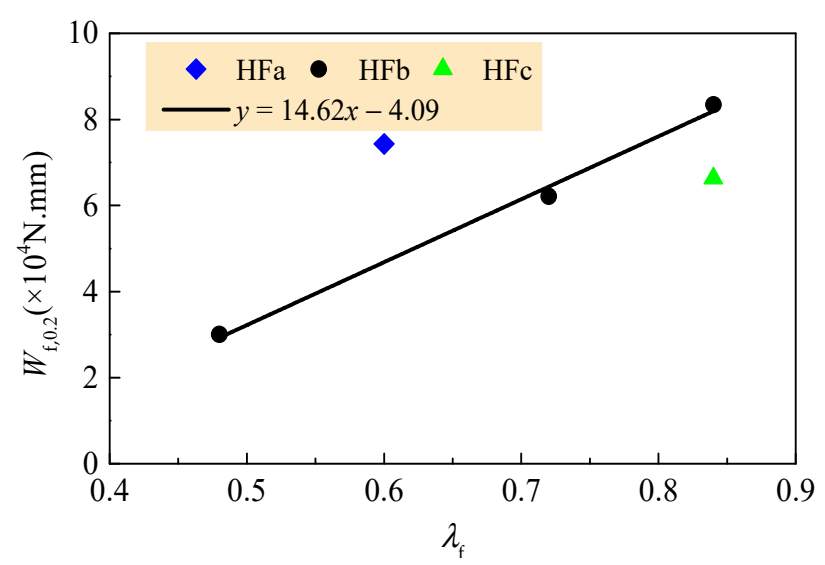

(a)

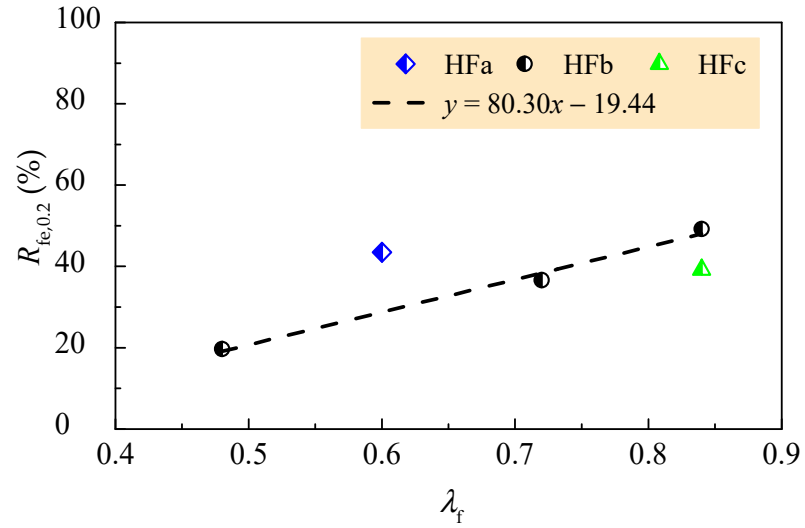

(b)

Figure 10. Axial tensile toughness changed with fiber factor: (a) tensile work; (b) toughness ratio.

\subsection{Discussion on Tensile Strengths}

The axial tensile strength of self-compacting $\operatorname{SFRC} f_{\text {at }}$ is higher than the splitting tensile strength $f_{\text {st }}$, the ratios vary from 1.09 and 1.27 with an average of 1.18 . The strengthening effect of steel fiber on the axial tensile strength is greater than that of splitting tensile strength. This is significantly different from that of vibrated SFRC [17,33,34]. It has been reported that for vibrated SFRC, the axial tensile strength is less than splitting tensile strength, and the strengthening effect of splitting tensile strength is greater than that of axial tensile strength [17].

This difference comes mainly down to the significantly different distribution of steel fibers in the self-compacting SFRC. Due to the flat cast of prism specimens, the steel fiber trend to orientation along the flow direction of self-compacting SFRC $[1,2,31]$. This direction is consistent with the axial tensile direction which benefits to the axial tensile resistance of the self-compacting SFRC. At the same time, this orientation is perpendicular to the load direction of the splitting tensile test [2,31]. The strengthening effect of steel fiber on tensile strength could not be developed until the initiation of the first spitting cracks. In this condition, the complex stress exists in the splitting section with the coupling of shear stress and tensile stress $[3,20]$. This weakens the action of steel fiber along the splitting tensile direction. Therefore, the adaptability of splitting tensile test is questionable to be used for the self-compacting SFRC.

\section{Conclusions}

Based on the test results of the splitting tensile strength and axial tensile properties of self-compacting SFRC, the main conclusions can be drawn as follows:

(1) The splitting tensile strength of self-compacting SFRC is positively correlated with fiber factor, and the prediction model considering the influences of fiber distribution and volume fraction is proposed.

(2) The axial tensile strength of self-compacting SFRC is positively correlated with fiber factor, and the prediction model of which is proposed considering the influences of fiber distribution and volume fraction. The axial tensile work and tensile toughness ratio are positively correlated with the volume fraction of steel fiber, while no obvious relationship with the fiber length.

(3) The strengthening effect of steel fiber on axial tensile strength is greater than that of splitting tensile strength. This reflects the real distribution of steel fiber along the flow direction of self-compacting SFRC.

(4) With the improvement of notching techniques, the forming of notched specimens become easier. The axial tensile test with notched specimen is a feasible method to evaluate the tensile properties of self-compacting SFRC. 
Author Contributions: Conceptualization, X.D. and M.Z.; methodology, C.L.; validation, J.L.; formal analysis, X.D.; investigation, H.G. and L.L.; data curation, X.D.; writting-original draft preparation, X.D.; writing-review and editing, M.Z. and C.L.; funding acquisition, X.D. and J.L. All authors have read and agreed to the published version of the manuscript.

Funding: This research was funded by National Key Research and Development Plan of China, grant number "2017YFC0703904"; Attracting Foreign Talents Fund of Henan, China, grant number "YWZ2018-6-HS2"; Natural Science Foundation of Henan, China, grant number "212300410192" and the Key Scientific and Technological Research Project of University in Henan, China, grant number “20A560015”.

Data Availability Statement: The data presented in this study are contained in this article.

Conflicts of Interest: The authors declare no conflict of interest.

\section{References}

1. Akcay, B.; Tasdemir, M.A. Mechanical behaviour and fibre dispersion of hybrid steel fibre reinforced self-compacting concrete. Constr. Build. Mater. 2012, 28, 287-293. [CrossRef]

2. Zhao, M.L.; Li, J.; David, L. Effects of flowability on SFRC fibre distribution and properties. Mag. Concr. Res. 2017, 69, 1043-1054. [CrossRef]

3. Khaloo, A.; Raisi, E.M.; Hosseini, P.; Tahsiri, H. Mechanical performance of self-compacting concrete reinforced with steel fibers. Constr. Build. Mater. 2014, 51, 179-186. [CrossRef]

4. Li, C.Y.; Geng, H.B.; Deng, C.H.; Li, B.C.; Zhao, S.B. Experimental investigation on columns of steel fiber reinforced concrete with recycled aggregates under large eccentric compression load. Materials 2019, 12, 445. [CrossRef]

5. Li, X.K.; Pei, S.W.; Fan, K.P.; Geng, H.B.; Li, F.L. Bending performance of SFRC beams based on composite-recycled aggregate and matched with 500MPa rebars. Materials 2020, 13, 930. [CrossRef]

6. Zhao, M.S.; Li, C.Y.; Su, J.Z.; Shang, P.R.; Zhao, S.B. Experimental study and theoretical prediction of flexural behaviors of reinforced SFRELC beams. Constr. Build. Mater. 2019, 208, 454-463. [CrossRef]

7. Martinelli, P.; Colombo, M.; Fuente, A.; Cavalaro, S.; Pujadas, P.; Prisco, M. Characterization tests for predicting the mechanical performance of SFRC floors: Design considerations. Mater. Struct. 2021, 54, 2. [CrossRef]

8. Martinelli, P.; Colombo, M.; Pujadas, P.; Fuente, A.; Cavalaro, S.; Prisco, M. Characterization tests for predicting the mechanical performance of SFRC floors: Identification of fibre distribution and orientation effects. Mater. Struct. 2021, 54, 3. [CrossRef]

9. Pereira, E.N.B.; Barros, J.A.O.; Camões, A. Steel fiber-reinforced self-compacting concrete: Experimental research and numerical simulation. J. Struct. Eng. 2008, 134, 1310-1321. [CrossRef]

10. Ferrara, L.; Park, Y.D.; Shah, S.P. A method for mix-design of fiber-reinforced self-compacting concrete. Cem. Concr. Res. 2007, 37, 957-971. [CrossRef]

11. MertYücel, Y.; Bülent, B.; Mehmet, A.S. Effect of fine to coarse aggregate ratio on the rheology and fracture energy of steel fibre reinforced self-compacting concretes. Sadhana 2014, 39, 1447-1469.

12. Silva, M.A.D.; Pepe, M.; Pfeil, M.S.; Pfeila, M.S.; Filho, R.D.T. Rheological and mechanical behavior of high strength steel fiber-river gravel self-compacting concrete. Constr. Build. Mater. 2017, 150, 606-618. [CrossRef]

13. Ghanbarpour, S. The Effect of type and volume fraction (VF) of steel fiber on the mechanical properties of self-compacting concrete. J. Eng. Des. 2010, 8, 247-256. [CrossRef]

14. Tameemi, W. Correlations Between Compressive, Flexural, and Tensile Behavior of Self-Consolidating Fiber Reinforced Concrete. Master's Thesis, University of Kansas, Lawrence, KS, USA, October 2015.

15. China Association of Engineering Construction Standardization. Test methods for steel fiber reinforced concrete. In CECS 13:2009; China Planning Press: Beijing, China, 2010.

16. Cao, D.F.; Fu, L.Z.; Qin, X.C.; Yang, Z.W. Tensile constitutive characteristics of concrete under freeze-thaw cycles. J. Jiangsu Univ. 2011, 32, 359-363.

17. Han, R.; Zhao, S.B.; Qu, F.L. Experimental study on tensile properties of steel fiber reinforced concrete. China Civ. Eng. J. 2006, 11, 67-71.

18. Shen, C.M.; Cui, Y.Y. Experimental study on tensile strength of concrete with steel slag and nano-SiO 2 . Concrete 2016, 11, 24-27.

19. Ministry of Housing and Urban-Rural Development of the People's Republic of China. Standard for test methods of concrete physical and mechanical properties. In GB/T 50081-2019; China Building Industry Press: Beijing, China, 2019.

20. Zhao, S.B. Design Principle of Concrete Structures; Tongii University Press: Shanghai, China, 2013.

21. Goaiz, H.A.; Farhan, N.A.; Sheikh, M.N.; Yu, T.; Hadi, M.N.S. Experimental evaluation of tensile strength test methods for steel fibre-reinforced concrete. Mag. Concr. Res. 2019, 71, 385-394. [CrossRef]

22. Khalaj, G.; Nazari, A. Modeling split tensile strength of high strength self compacting concrete incorporating randomly oriented steel fibers and $\mathrm{SiO}_{2}$, Nanoparticles. Compos. B Eng. 2012, 43, 1887-1892. [CrossRef]

23. You, Z.G.; Tao, Z.Q.; Xu, G.Q.; Han, Y.T.; Zhou, Y.L. Experimental study on axial tensile strength of hybrid fiber reinforced self-compacting concrete. Struct. Eng. 2019, 35, 202-208. 
24. Clifford, A.O.O.; David, W.B.; Stephanie, J.B.; Nikos, N. Behaviour of hybrid steel fibre reinforced self compacting concrete using innovative hooked-end steel fibres under tensile stress. Constr. Build. Mater. 2019, 202, 753-761.

25. Cunha, V.M.C.F.; Barros, J.A.O.; Sena-Cruz, J.M. An integrated approach for modelling the tensile behaviour of steel fibre reinforced self-compacting concrete. Cem. Concr. Res. 2011, 41, 64-76. [CrossRef]

26. Liao, W.C.; Chao, S.H.; Park, S.Y.; Naaman, A.E. Self-Consolidating High Performance Fiber Reinforced Concrete (SCHPFRC)Preliminary Investigation. Report No. UMCEE 06. 2006. Available online: https://www.rilem.net/publication/publication/58 ?id_papier=9603 (accessed on 25 February 2021).

27. Ding, X.X.; Zhao, M.L.; Li, J.; Shang, P.R.; Li, C.Y. Mix proportion design of self-compacting SFRC with manufactured sand based on the steel fiber-aggregates skeleton packing test. Materials 2020, 13, 2833. [CrossRef]

28. Ding, X.X.; Zhao, M.L.; Zhou, S.Y.; Fu, Y.; Li, C.Y. Statistical analysis and preliminary study on the mix proportion design of self-compacting steel fiber reinforced concrete. Materials 2019, 12, 637. [CrossRef] [PubMed]

29. Ministry of Housing and Urban-Rural Development of the People's Republic of China. Technical specification for application of self-compacting concrete. In JGJ/T 283-2012; China Architecture \& Building Press: Beijing, China, 2012.

30. RILEM TC 162-TDF. Test and design methods for steel fiber reinforced concrete, bending test. Mater. Struct. 2002, 35, 579-582. [CrossRef]

31. Ding, X.X.; Li, C.Y.; Han, B.; Lu, Y.Z.; Zhao, S.B. Effects of different deformed steel-fibers on preparation and fundamental properties of self-compacting SFRC. Constr. Build. Mater. 2018, 168, 471-481. [CrossRef]

32. Ding, X.X.; Zhao, M.L.; Li, C.Y.; Li, J.; Zhao, X.S. A multi-index synthetical evaluation of pull-out behaviors of hooked-end steel fiber embedded in mortars. Constr. Build. Mater. 2021, 276, 122219. [CrossRef]

33. Zhao, M.L.; Zhao, M.S.; Chen, M.H.; Li, J.; David, L. An experimental study on strength and toughness of steel fiber reinforced expanded-shale lightweight concrete. Constr. Build. Mater. 2018, 183, 493-501. [CrossRef]

34. Zhao, S.B.; Li, C.Y.; Du, H.; Qian, X.J. Experimental study on steel fiber reinforced high strength concrete with large size aggregate. J. Build. Mater. 2010, 13, 155-160. 